Itinerarios culturales y rutas turístico-culturales 11

\title{
Rutas culturales y turismo en el contexto español
}

Juan Ignacio Rengifo Gallego. Profesor asociado. Universidad de Extremadura

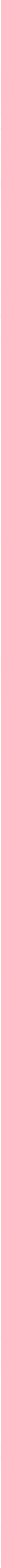




\section{Resumen}

El número de viajeros se viene incrementando de forma paulatina durante las últimas décadas. Este crecimiento ha incidido en la segmentación del mercado, provocando la aparición y desarrollo de numerosas modalidades turísticas entre las que ha adquirido un especial protagonismo el denominado turismo cultural. Para dar respuesta a esta demanda, instituciones y touroperadores cuentan con un amplio elenco de propuestas y productos. Una de las actividades más solicitadas es la oferta de rutas o itinerarios turísticos culturales, cuyo diseño responde a diferentes criterios. Esta realidad es palpable en ferias de la dimensión de FITUR y en las páginas web oficiales de turismo de las comunidades autónomas, donde todo lo que está relacionado con el turismo cultural, como eventos o itinerarios basados en recursos patrimoniales, adquiere una especial relevancia.

\section{Palabras clave}

Comunidades autónomas I España I Evolución I FITUR | Internet I Itinerarios culturales I Recursos culturales I Turismo cultural I 2006
Q El Camino del Cid se configura a partir del trazado literario definido en el Cantar del Mío Cid ( S. XII-XIII ). En la imagen, relieve de Soldados del Claustro de Santo Domingo de Silos, Burgos / Consorcio Camino del Cid
El turismo es uno de los mayores vehículos de intercambio cultural que se acrecienta en la medida que aumenta el número de viajeros internacionales. Este crecimiento viene inducido por el proceso de internacionalización en el que estamos inmersos, donde los medios de transportes y la accesibilidad tienen un protagonismo directo que contribuyen a la permeabilidad de los territorios. En este sentido son claros los datos que of rece la Organización Mundial del Turismo que indican cifras de 9 dígitos (763 millones) para cuantificar los movimientos de viajeros internacionales en el año 2004 (OMT, 2006), a los que habría que agregar las de los turistas internos que se mueven dentro de cada país y que incrementarían las cantidades globales de forma ingente. Sólo en España, el número de viajes derivados del turismo interno en el año 2005 (enero-septiembre) superó la cifra de 100 millones de turistas (Instituto de Estudios Turísticos, 2006a). La tendencia al alza de estas cifras se viene manifestando en las últimas décadas en las seis regiones en las que la Organización Mundial del Turismo divide el planeta: África, Oriente Medio, América, Asia Meridional, Asia Oriental/Pacífico y Europa. Por citar referentes cuantitativos recientes, of recidos por la OMT, hemos de indicar que se ha pasado de los 441 millones de turistas del año 1990 a los 763 millones de 2004 , recayendo el mayor volumen de turistas en Europa, cuya cuota de mercado, en el 2004 , se situó en el $54,5 \%$, seguida, a una considerable distancia por Asia y el Pacífico con el $20 \%$, América 16,5\%, Oriente Medio 4,6\% y África con el $4,4 \%{ }^{1}$. Con estos datos se deduce que Europa ejerce un claro liderazgo como región emisora y receptora de turistas, ya que la mayor parte de los movimientos que se registran, dentro de su territorio, tienen un carácter intra-regional, aunque existen claros desequilibrios entre unas zonas y otras. Por subregiones europeas habría que remarcar a la cuenca mediterránea como destino más importante, figurando Francia (75 millones), España (53 millones) e Italia (37 millones) a la cabeza de los países que han recibido el mayor número de turistas internacionales en el año 2004. No obstante, en la serie histórica de la evolución del turis- 


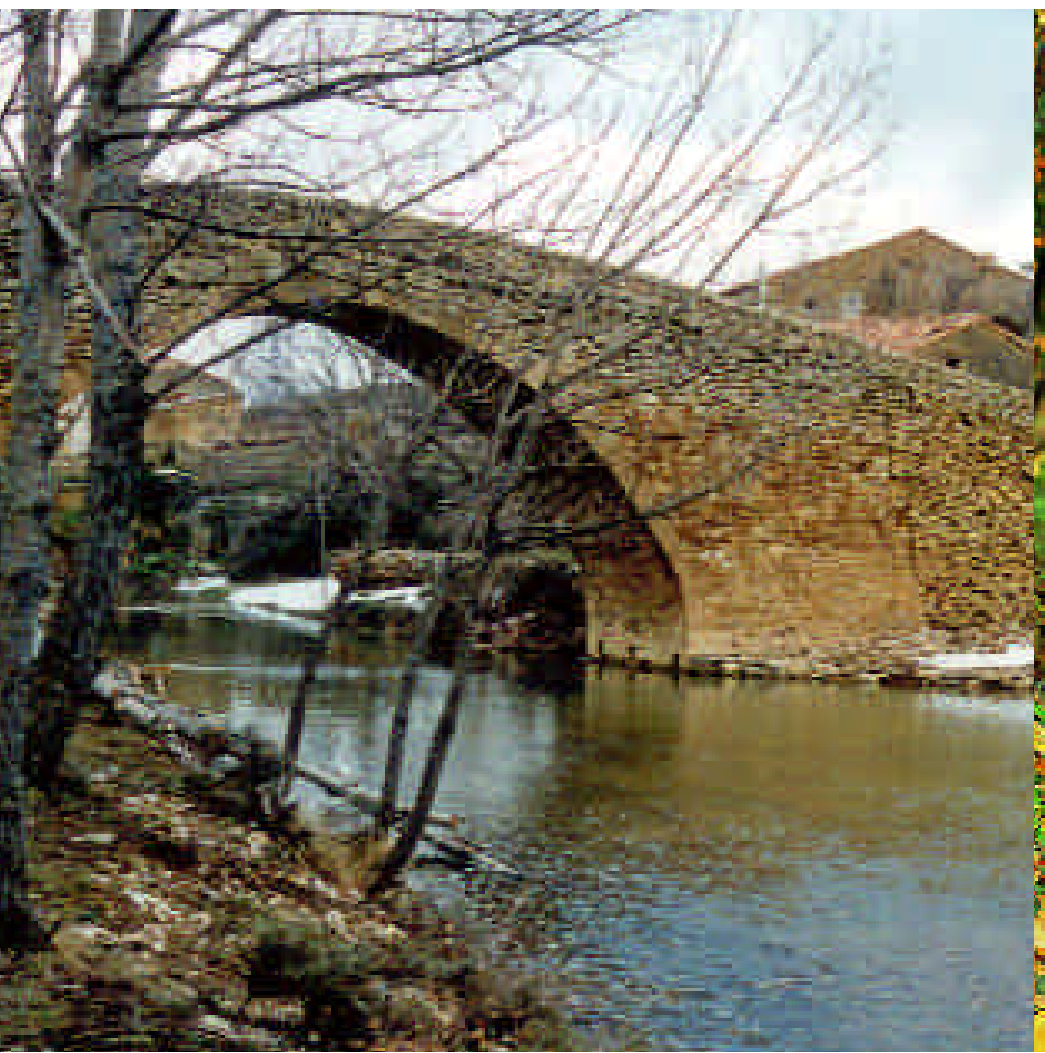

W El eje principal del Camino del Cid parte de Vivar del Cid -patria chica de don Rodrigo-, y muere en la ciudad de Valencia. Aquí, Villafranca del Cid / Pablo José Fontanet Gil. Consorcio Camino del Cid

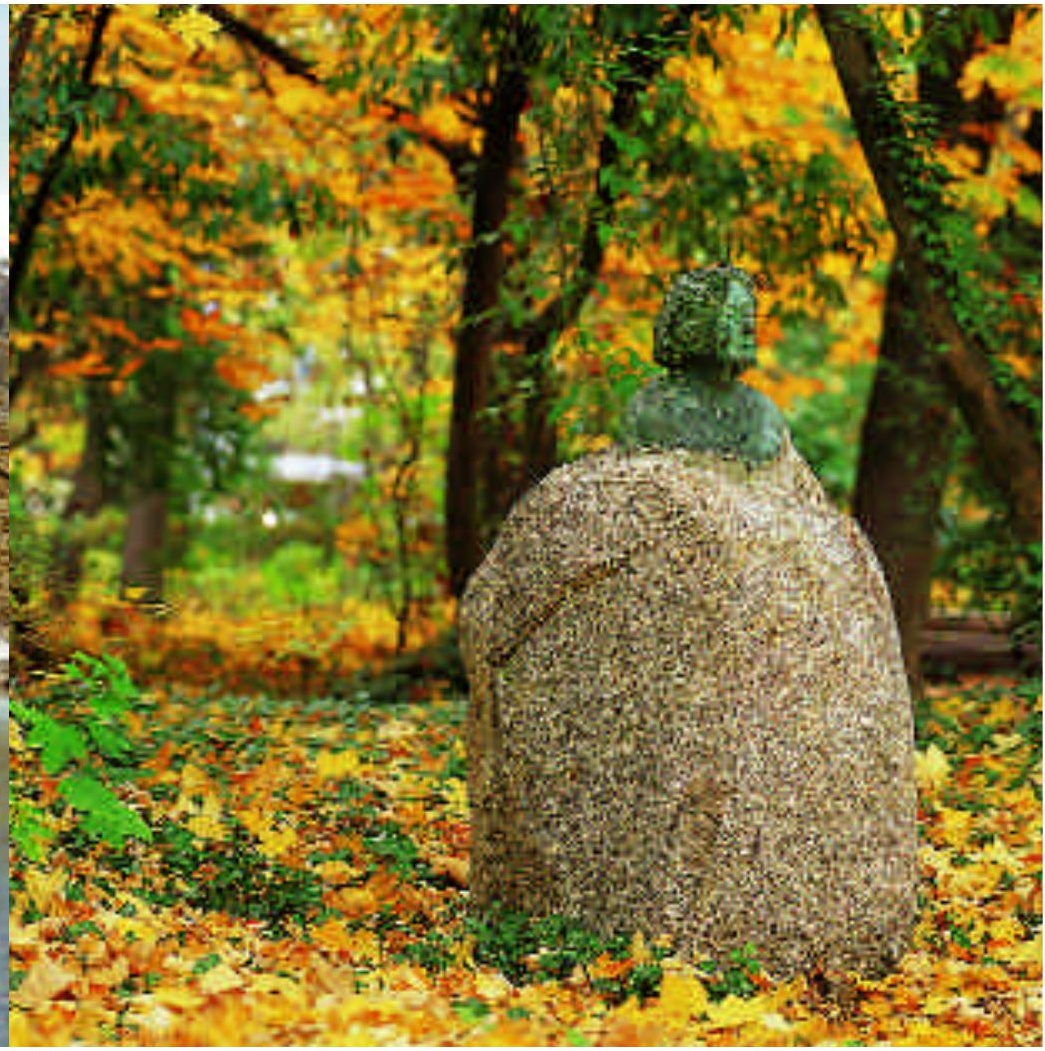

W Busto de la escritora Rosa Chacel en los Jardines Campo Grande de Valladolid. Camino de la Lengua Castellana / Fundación CAmino de LA Lengua Castellana mo, se aprecia cierta pérdida de cuota de mercado del viejo continente, atribuible a la aparición de nuevos escenarios turísticos, denominados emergentes, como son los destinos asiáticos. Esta situación ha desembocado en la existencia de un gran mercado turístico que se reparte por cientos de países del planeta, en la medida en que son puestos en valor nuevos destinos y se diversifican las motivaciones.

Por todo ello, con estos volúmenes de turistas es lógico pensar que no todos viajen bajo un mismo patrón de conducta. De ahí que, bajo este punto de vista, en el turismo actual se aprecien una serie de elementos relevantes:

j Distribución entre numerosos destinos repartidos por toda la geografía mundial.

j Fraccionamiento de los viajes a lo largo de todo el año, aunque haya períodos de una demanda más intensa.

j Desplazamientos por motivos muy diversos.

En relación con este último elemento, hay que señalar que del crecimiento cuantitativo del turismo se deriva la segmentación del mercado y, en función de este fenómeno, se desarrollan distintos tipos de turismo. La nómina de tipos o modalidades de turismo es amplia y difícil de precisar con exactitud, aunque, generalmente, se mencionan: turismo religioso, turismo de sol y playa, turismo de congresos, turismo de naturaleza, turismo cultural, turismo rural, turismo deportivo o turismo de balnearios, entre otros. Algunos de ellos se identifican con el denominado turismo de masas, ligado, principalmente, a espacios de litoral y, en ocasiones, urbanos; $y$ otros, por el contrario, son identificados con turismos menos masivos como pudieran ser los denominados turismos alternativos unidos, principalmente, a determinadas parcelas de la cultura y la naturaleza. En ocasiones encontraremos, incluso, "tipos de turismos" que formarán parte del futuro, más que del presente y cuya expresión más radical podrían ser los estrambóticos y escasos viajeros espaciales dispuestos a desprenderse de varias decenas de miles de euros por vivir una experiencia al alcance de pocos mortales ${ }^{2}$.

Todos los datos y factores citados demuestran la dinámica positiva en la que se encuentra el turismo, aunque esta actividad sigue siendo muy sensible a cuestiones de orden coyuntural. El turismo crece y lo hace en distintas direcciones, atendiendo a las motivaciones como uno de los 


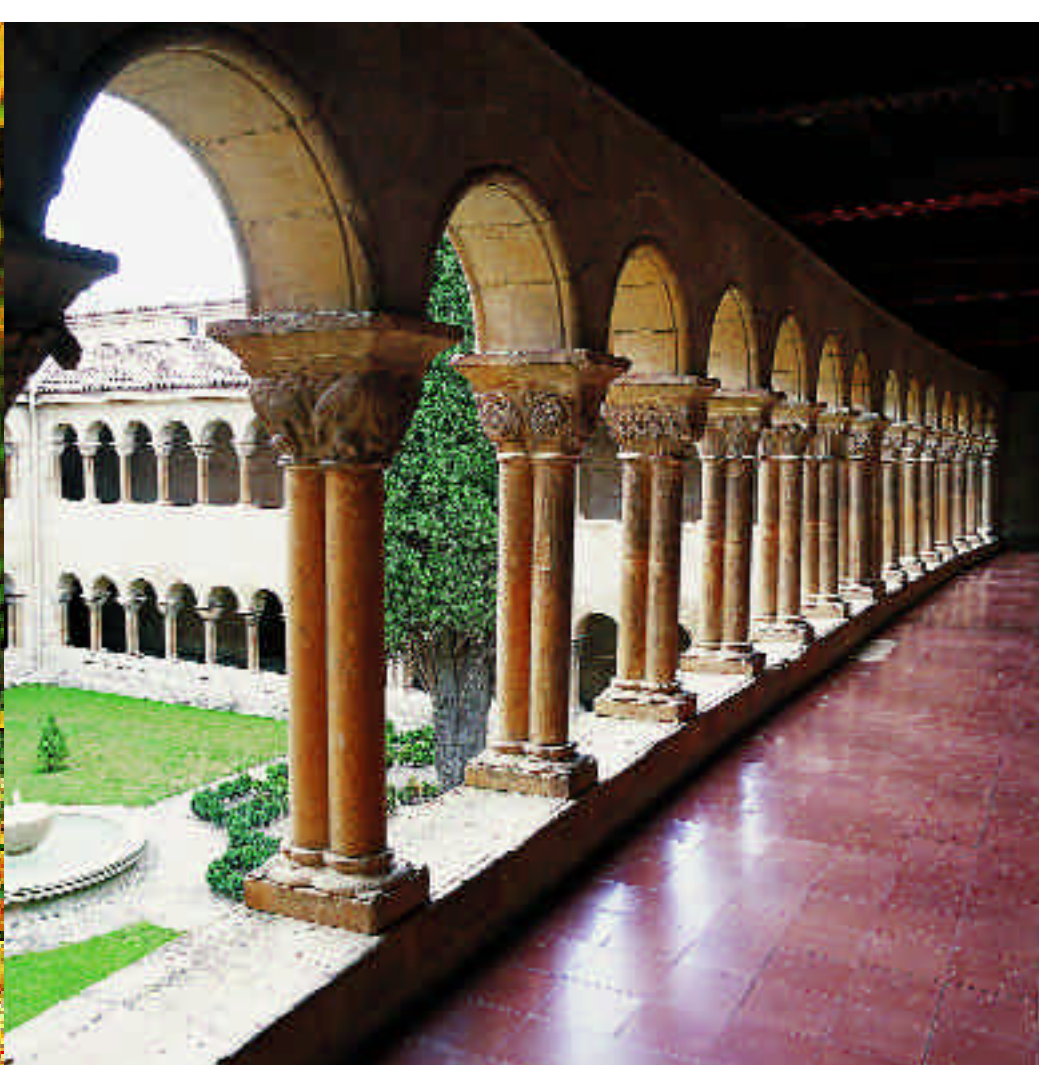

W Monasterio de Santo Domingo de Silos (Burgos), uno de los hitos del Camino de la Lengua, junto a San Millán, Valladolid, Salamanca, Ávila y Alcalá de Henares / Fundación Camino de la Lengua Castellana

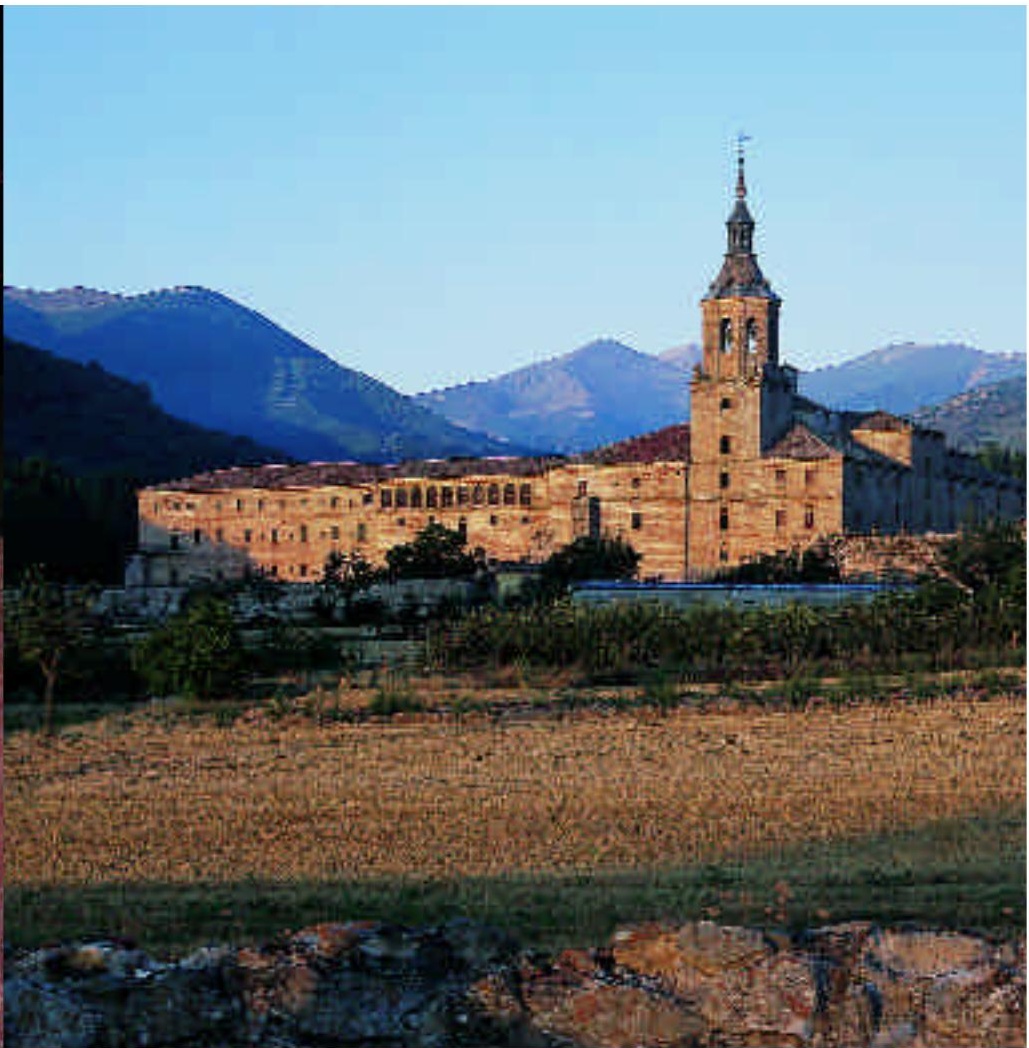

W Monasterio de Yuso en San Millán de la Cogolla (La Rioja), declarado en 1997 Patrimonio de la Humanidad. En él se escribieron hace más de un milenio las primeras palabras en castellano / Fundación CAMINO DE LA Lengua Castellana ejes fundamentales. En este panorama, el turismo cultural se ha convertido en una de las modalidades más demandadas como refrendan algunos datos. Citando el ejemplo de España, el 81,8\% de turistas que llegaron a nuestro país desde el extranjero, en el año 2004, lo hicieron por motivos de ocio y vacaciones. A su vez, de éstos, un 16,7\% declararon hacerlo por motivos culturales, lo que convierte a éste en el segundo colectivo más numeroso de turistas internacionales en España (Instituto de Estudios Turísticos, 2006b). Esta cifra se ve reforzada por el hecho de que un $54,1 \%$ de los turistas extranjeros reconocieron haber realizado actividades culturales durante su estancia, lo que convierte a estas actividades en las más practicadas ese año ${ }^{3}$. En cuanto al turismo interno, el realizado por los españoles dentro de nuestro país, la modalidad cultural aparece como principal motivación en un 15,8\%. Además, en un $37,3 \%$ de los viajes internos se hicieron visitas culturales y en un 8,6\% acudieron a espectáculos culturales (Instituto de Estudios Turísticos, 2006c). Ambas referencias estadísticas prueban que el volumen de turistas culturales es muy elevado, por lo que no es de extrañar que exista un interés por promocionar todo lo relacionado con esta modalidad y ofertar un importante número de paquetes turísticos, por medio de tour operadores especializados, en esta parcela del turismo.

\section{LAS RUTAS PATRIMONIALES: UNO DE LOS PILARES DEL TURISMO CULTURAL}

En tanto que el turismo cultural es un concepto que incluye llevar a cabo actividades que permitan experimentar la cultura NÁZQUEZ, 2005), conviene señalar que entre esas actividades se incluyen las rutas turísticas cut turales. Estas rutas son uno de los recursos más frecuentes, al que recurren los organismos públicos y los operadores turísticos para promocionar un destino 0 vender un producto, respectivamente. La razón se encuentra en el propio concepto de turismo que va ligado al desplazamiento $y$, en esta dirección, los itinerarios son fiel reflejo de ese turismo itinerante que exige ir de un lugar a otro siguiendo unas pautas determinadas. Con estas rutas se consiguen distintos efectos positivos como el aumento de la estancia media del turista en el destino, quizás uno de los handicaps que se marcan todos los agentes turísticos públicos y privados; el reparto de los beneficios económicos y sociales de una forma más extensa por el territorio y la recuperación-puesta en valor de un mayor número de recursos patrimoniales.

La extensa of erta de rutas turísticas culturales, en nuestro entorno, se debe a la posibilidad de conjugar factores relacionados con la cantidad, 


\section{En los últimos tiempos, el interés por poner en valor nuevos recursos culturales ha llevado al diseño de rutas basadas en recursos escasamente explotados}

la diversidad y la amplia dispersión espacial de los recursos turísticos que conforman la materia prima con la que se elaboran los itinerarios. $\mathrm{Si}$ utilizamos como ejemplo la variedad de recursos habría que hablar de una amplia tipología de elementos en la que cabría hablar de monumentos, conjuntos histórico artísticos, patrimonios de la humanidad, fiestas de interés turístico, museos o actividades programadas, entre otros.

Para comprender adecuadamente la of erta de rutas, it inerarios o circuitos culturales hay que distinguir entre dos tipos, de acuerdo con el tipo de of ertante:

1. Rutas o itinerarios de turismo cultural ofertados desde instituciones. En este caso, la mayor parte de las rutas ligadas al patrimonio cultural se basa en recursos que tienen lazos comunes (históricos, artísticos...), tal y como veremos más adelante en el análisis realizado en FITUR y en las páginas web oficiales de turismo de las distintas comunidades, aunque eso no evita que haya rutas heterogéneas en las que los recursos son muy variados. Entre las primeras cabría hablar, por ejemplo, de rutas temáticas sobre determinados estilos artísticos (románico, gótico, mudéjar o barroco) 0 de rutas ligadas a una arquitectura concreta (castillos o monasterios), mientras que, en el segundo caso, nos referiríamos a rutas territoriales en las que se incluyen todo tipo de recursos con atractivo turístico (rutas comarcales o rutas de fines de semana). En los últimos tiempos, el interés por poner en valor nuevos recursos culturales ha llevado al diseño de rutas basadas en recursos escasamente explotados, como pudieran ser la arquitectura industrial o vernácula, por citar algunos ejemplos ${ }^{4}$.

Estas rutas de turismo cultural no se deben confundir con los itinerarios culturales aunque eso no quita que determinados itinerarios culturales, como los que han sido declarados como tal por el Consejo de Europa 0 han sido reconocidos Patrimonio de la Humanidad, sean punto de referencia para el turismo cultural. Es factible comprobar cómo se recurre a estas designaciones para dar un mayor realce y captar la atención del turista. Este proceder se aprecia no sólo en la promoción institucional, sino también en los operadores turísticos especializados que, con frecuencia, acuden a estas denominaciones para realzar el at ractivo de las rutas o circuitos propuestos ${ }^{5}$.

2. Rutas o circuitos de turismo cultural ofertados por operadores turísticos. Los tour operadores lanzan al mercado productos turísticos dirigidos a consumidores con interés por el turismo cultural. A ellos se dirigen estos productos turísticos consistentes en la prestación de servicios que no constituyen un bien material (VOGELER Y HERNÁNDEZ, 1999). Uno de los productos estrella son los circuitos ${ }^{6}$, viajes combinados ${ }^{7}$ que incluyen una serie de servicios entre los que se encuentran, generalmente, el transporte, alojamiento, manutención y algún tipo de visita. En los últimos años ha crecido la of erta del "todo incluido" en el turismo cultural, acepción arraigada al turismo de sol y playa ${ }^{8}$ en países caribeños y otras regiones del mundo pero que no se corresponde exactamente con lo que estamos 
hablando. El "todo incluido" en circuitos culturales of ertado por operadores turísticos a través de la red de agencias de viajes minoristas incluye, además del transporte, alojamiento y manutención, otros servicios como visitas con guías y entradas a monumentos ${ }^{9}$. Con este sistema el turista conoce el importe final del paquete, ya que en otras ocasiones las visitas panorámicas y con guías no están incluidas y hay que abonarlas en destino.

Los productos turísticos de los que estamos hablando son comercializados bajo la modalidad de a la of erta. Estas rutas se plasman en folletos y son distribuidas a través de miles de agencias de viajes minoristas. casi 8.000 agencias de viajes en España en el año 2004 (INE, 2006)En cualquier agencia de viajes minorista es fácil acceder a un elevado número de folletos en los que se ofertan todo tipo de destinos. Las mayoristas, cuando sacan al mercado folletos con itinerarios programados, asumen un riesgo ya que llevan a cabo la distribución y promoción del material sin tener asegurada la venta. Otra parte del mercado es constituida por los productos de turismo cultural a la demanda, en cuyo caso, el diseño puede ser llevado a cabo por una mayorista o una minorista que venda directamente a su cliente, en función de las indicaciones, o no, de este último. Sin ir más lejos, en Europa hay varios cientos de agencias mayoristas comercializando productos de turismo cultural con destino España (BOTE, 2000), lo que nos da una idea del papel que vienen jugando en los últimos tiempos.

Para evaluar la of erta de programas y folletos sobre turismo cultural, en general, por parte de las instituciones turísticas, nos hemos basado en el material con el que contaban los distintos stands de las comunidades autónomas en FITUR 2006. La feria internacional de turismo de Madrid, conviene recordar, es uno de los escaparates más importantes del mundo con una superficie de exposición bruta, en la pasada exposición, de 150.000 metros cuadrados, 12.415 empresas expositoras entre titulares y coexpositores, 170 países participantes y decenas de miles de participantes profesionales procedentes de todo el mundo (FITUR, 2006). El área nacional, con la presencia de numerosos organismos oficiales, es uno de los más representados, donde, especialmente, las comunidades autónomas ocupan un gran espacio y concentran buena parte de las visitas de profesionales. Además, estas instituciones aprovechan el evento para presentar nuevo material promocional ante la prensa y profesionales. Pero no sólo están presentes las comunidades autónomas pues también es amplia la relación de mancomunidades y ayuntamientos. Estas últimas tratan de dar respuesta a ese creciente turismo urbano, que es difícil de diferenciar, a veces, del turismo cultural, aumentando su of erta cultural a través de eventos y equipamientos como museos (CALLE Y GARCÍA, 2004). Por estas circunstancias, FITUR era un lugar apropiado para analizar la oferta de turismo cultural existente a nivel nacional, prestando especial atención a todo lo relacionado con rutas. Para obtener la información se visitaron los stands de las comunidades autónomas. A tenor de la información obtenida se pueden plantear las siguientes cuestiones:
1. La oferta de turismo cultural es uno de los bastiones en los que las comunidades autónomas basan su promoción turística.

2. La of erta de turismo cultural existente es muy amplia. En ella participan no sólo los organismos responsables del turismo de las instituciones autonómicas, sino que también toman parte en esta divulgación ayuntamientos, mancomunidades de municipios, comarcas y patronatos de turismo, entre otros. Por ello es habitual que mucha información se solape y sea reincidente.

3. La of erta de turismo cultural se articula alrededor de la información descriptiva del patrimonio y en base a rutas o itinerarios, más o menos detallados, puesto que la metodología, a la hora del diseño, varía ostensiblemente. Los ayuntamientos of recen rutas urbanas, las mancomunidades rutas comarcales, los patronatos provinciales de turismo rutas comarcales 0 intercomarcales dentro de su provincia y las comunidades autónomas rutas de mayor rango territorial.

4. En el apartado de las rutas o itinerarios, existe la tendencia a promocionar estas actividades en función del tiempo de duración, destacando las rutas cortas, asociadas a los fines de semana, por un lado, y los grandes recorridos, por ot ro.

5. Las rutas de carácter cultural y gran recorrido, dirigidas a caminantes, reciben una intensa promoción, aunque se echa en falta una perspectiva interregional. Esta perspectiva es importante en itinerarios que atraviesan varias comunidades autónomas como la Vía de la Plata, el Camino de Santiago o el Camino de la Lengua Castellana, por citar algunos ejemplos.

6. Las rutas que han recibido el reconocimiento de Itinerario Cultural del Consejo de Europa o Patrimonio de la Humanidad reciben un notable impulso promocional con fines turísticos.

7. Existen diferencias entre unas comunidades y otras a la hora de combinar los recursos que forman parte del turismo cultural. Hay coincidencia a la hora de incluir conjuntos históricos artísticos, monumentos 0 museos, pero diferencias a la hora de incluir otros elementos.

8. Se definen y diseñan rutas en función de áreas temáticas (idéntico estilo artístico, mismo período cronológico...) y heterogéneas donde se mezclan todo tipo de recursos (naturaleza, culturales...).

\section{LA OFERTA DE TURISMO CULTURAL EN INTERNET}

Si FITUR es un claro referente para la promoción turística que realizan las comunidades autónomas, especial relevancia tiene en la sociedad actual, también, Internet. Para conocer la oferta de turismo cultural, 


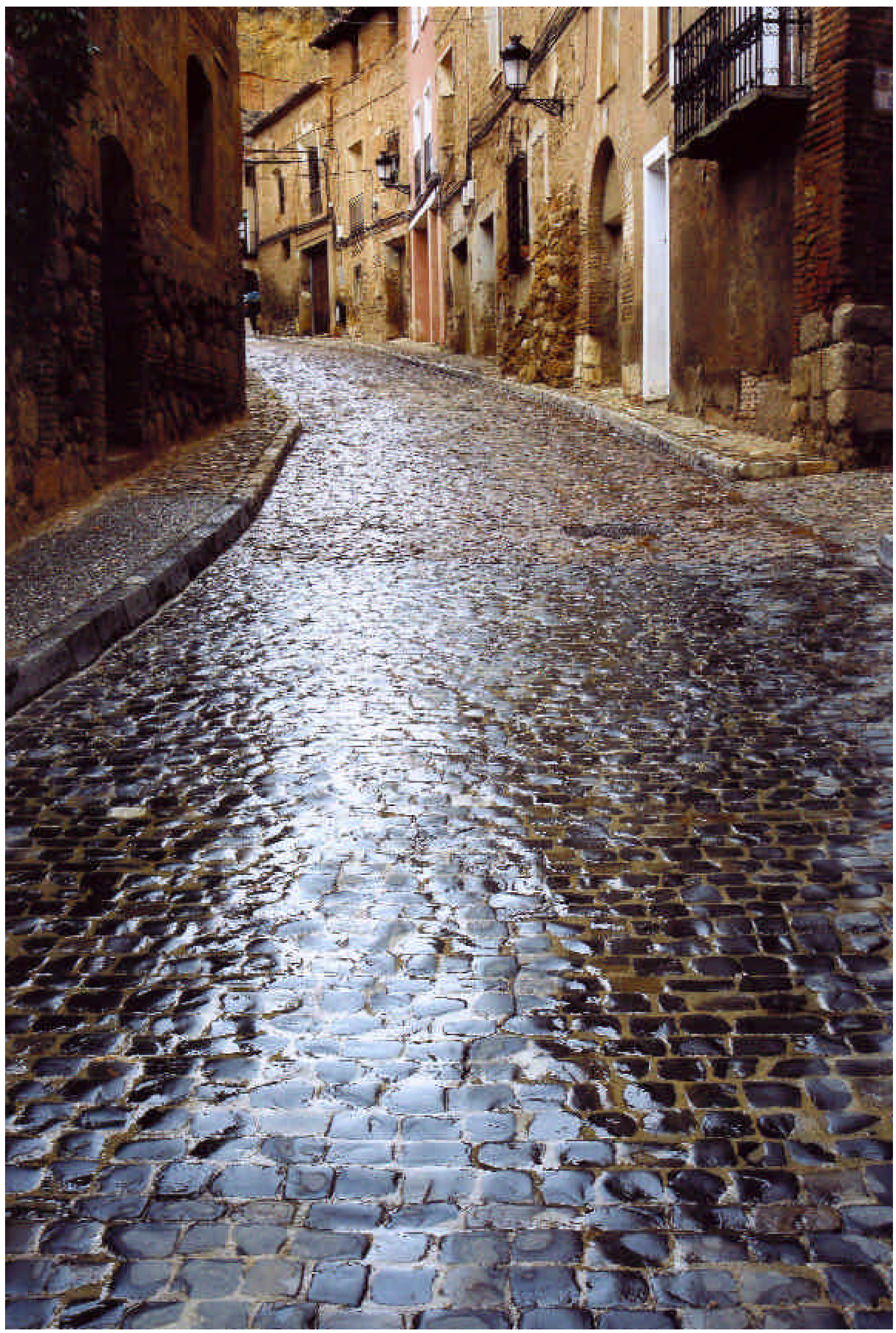


Q Calle de Daroca, Zaragoza. Inicio del denominado "Anillo de

Gallocanta”, itinerario de naturaleza senderista que une Daroca con

Gallocanta, lugar que algunos estudiosos señalan como el "Alucad"

citado en el Cantar / Ramón Sanz Frax. Consorcio Camino del Cid especialmente de rutas 0 itinerarios turísticos culturales, a través de este medio, se ha procedido de la siguiente forma:

1. Localizar y consultar las páginas web oficiales de turismo de las distintas comunidades autónomas, durante los meses de mayo y junio de 2006. La referencia temporal es importante pues los contenidos pueden variar de fondo y forma.

2. Chequear si se of ertan, a través de este medio, rutas cuyo contenido se base en los recursos culturales.

3. Identificar si disponen de buscadores de recursos patrimoniales con los que los turistas puedan auto confeccionarse itinerarios.

4. Comprobar si disponen de agendas culturales en las que se reflejen las principales actividades culturales programadas.

Del examen de los contenidos de la forma expuesta, podemos extraer una serie de cuestiones:

1. En casi todos los casos aparece identificado el turismo cultural, desde la página de inicio, como uno de los pilares más importantes de la promoción turística ${ }^{10}$.

2. Todas las comunidades muestran un gran interés por tener actualizada una agenda cultural que permita conocer las actividades programa das. Dentro de éstas se incluyen exposiciones, representaciones teatrales, fiestas de interés turístico, celebraciones deportivas, conciertos, visitas guiadas y extensa oferta de actividades culturales, cuya información se pone a disposición del turista potencial a través de una agenda. Estas actividades constituyen, para los turistas en destino, un complemento $y$, en otras ocasiones, una motivación principal para llevar a cabo el viaje, celebrándose a lo largo de todo el año numerosas actividades culturales. En algunos casos, la agenda constituye uno de los elementos más importantes, dentro de la página de inicio, para captar la atención del turista sobre algún o algunos eventos en particular.

3. Las rutas turísticas son uno de los elementos más desarrollados. Dentro de las rutas dominan las que responden a un carácter temático ${ }^{11}$ y las que lo hacen siguiendo un modelo territorial. En ambos casos, los itinerarios propuestos no están sometidos a un ritmo temporal preciso como se produce en la of erta de productos turísticos de los operadores turísticos, aunque sí facilitan la movilidad del turista por el territorio, a través de la información incluida. No obstante, un turista que quiera seguir una de estas rutas debe completar la información con la oferta de servicios que existen en la zona y que suele aparecer en otros lugares de la página.

4. Recursos. En todos los casos es factible acceder a buscadores que permitan conocer el patrimonio por localidades. La forma de acceso es varia- ble ya que ésta se puede llevar a cabo por tipología del patrimonio o por la relación de municipios. Ésta es una herramienta válida para el turista individual que se elabora su itinerario y, por ello, necesita conocer detalles precisos sobre localización, descripción y horarios. En este sentido, la información incluida es muy extensa aunque, en algunos casos, enrevesada.

Tras el examen de las páginas de Internet ${ }^{12}$, pasamos a efectuar un comentario sobre los aspectos referidos a los puntos señalados con anterioridad por comunidades autónomas:

\section{j Andalucía}

La información sobre rutas turísticas culturales, que aparece en la página web, es muy amplia y aparece agrupada en tres grandes apartados: Arte y patrimonio, costumbres y tradiciones populares y otras rutas de interés. En el grupo de rutas de arte y patrimonio se incluyen diez tipos de rutas de gran diversidad: rutas de Andalucía americana a través de la arquitectura, rutas de Andalucía antigua, rutas de Andalucía barroca, rutas de Andalucía islámica, rutas de Andalucía renacentista, rutas de Andalucía romántica, rutas de castillos y monasterios de Andalucía, rutas de obras maestras de Andalucía, rutas de la arquitectura del siglo XX de Andalucía y rutas del gótico y mudéjar de Andalucía. En total, más de 60 propuestas de rutas incluidas en alguna de las agrupaciones comentadas anteriormente. En cuanto a las rutas de costumbres y tradiciones populares están dedicadas al mundo taurino, la artesanía o fiestas populares. Por último hay que mencionar tres grandes itinerarios ligados a la historia incluidos en el apartado denominado otras rutas: Ruta Bética-romana, Ruta del Tempranillo y Rutas del Legado Andalusí (7 rutas). Esta última es Gran Itinerario Cultural Europeo y, en Fitur, tenía un especial protagonismo promocional. Además de la amplia oferta de rutas, el turista con interés por conocer las actividades culturales cuenta con una agenda.

\section{j Aragón}

Las rutas turísticas culturales propuestas son muy diversas, destacando la ruta del mudéjar en la que se incluyen distintos destinos de gran valor por su riqueza artística (Patrimonio Mundial). Otras rutas destacadas son los Caminos de Santiago (camino francés, camino catalán, camino valenciano y camino jacobeo del Ebro), ruta de los monasterios, ruta del románico, ruta Mariana, ruta de los castillos y ruta de Goya en Aragón. Otro punto de interés relacionado con el turismo cultural son los denominados parques culturales considerados como un "territorio que contiene elementos relevantes del patrimonio cultural, integrado en un marco físico de valor paisajístico y ecológico singular que goza de promoción y protección global, con especiales medidas de salvaguarda para sus valores destacados". Los parques cut turales mencionados son cinco: Río Martín, Albarracín y Maestrazgo en Teruel y Río Vero y San Juan de la Peña en Huesca.

\section{j Asturias}

En Asturias, los grandes itinerarios adquieren un notable protagonismo, donde destacan dos rutas culturales de carácter interregional como son 
la Vía de la Plata y el Camino de Santiago con sus dos alternativas (interior y costa). Estos itinerarios aparecen reflejados dentro de las ofertas de cada una de las comunidades por las que discurren por su incuestionable interés. Para los que deseen "fabricarse" sus propios rutas, existe la posibilidad de conocer los recursos patrimoniales de forma agrupada, en cuyo caso se diferencian los siguientes: arqueología, prerrománico, instalaciones culturales, arquitectura religiosa, arquitectura popular, monumentos, edificios de interés, música y folclore, leyendas y mitologías, etnografía y conjuntos histórico-artísticos.

\section{j Cantabria}

Senderos y rutas son dos de las propuestas que se of ertan para recorrer Cantabria. Los senderos van orientados hacia el caminante que desea conocer algunos de los enclaves naturales más interesantes de los distintos territorios. La oferta de senderos a nivel nacional es muy elevada, debido a su creciente demanda y al interés por señalizar debidamente los itinerarios. En cuanto a las rutas cántabras de corte cultural destacan el Camino de Santiago y la ruta de peregrinación a Santo Toribio de Liébana, que este año vive una conmemoración especial. Al igual que en otros casos los recursos patrimoniales son accesibles a través de buscadores que permiten su localización por municipios.

\section{j Castilla la Mancha}

El eje central de las rutas ofertadas por Castilla la Mancha se centra en la Ruta de Don Quijote, con motivo del IV centenario de la publicación de la obra, en la que aparecen diez tramos que, a su vez, se dividen en distintas etapas. Además de esta ruta, la oferta, en cuanto a itinerarios, es mucho más amplia y afecta a todo el territorio. En cuanto a los recursos, estos pueden ser visitados a través del apartado de "Conoce la región" en el que se abren opciones para localizar recursos patrimoniales por tipología 0 ubicación. También tienen su protagonismo las fiestas populares, la artesanía o la agenda en la que se recogen eventos culturales.

\section{j Castilla y León}

Dedica al turismo cultural un gran volumen de información y rutas ligadas a las ciudades patrimonio, grandes itinerarios culturales y otros elementos. En el apartado de turismo cultural hay una extensa relación de secciones que guardan una relación entre sí: castillos, monasterios, sitios reales, catedrales, patrimonio de la humanidad, arqueología, arquitectura popular, cur tura popular, fiestas, Semana Santa, espacios culturales, museos y universidades. Al igual que en otros casos, uno de los apartados más desarrollados es el de las rutas culturales donde se exponen varias posibilidades: grandes rutas, rutas de fin de semana, rutas del vino y ciudades patrimonio. El apartado de grandes rutas está dedicado a los principales referentes en la comunidad autónoma: Camino de Santiago, Canal de Castilla, ruta del Duero, ruta de Carlos V, Camino de la Lengua Castellana, Ruta del Cid, Cañadas y Vías Verdes. También hay que mencionar, como referente importante del turismo cultural que ha atraído un número importante de turistas, la exposición de Las Edades del Hombre.

\section{j Cataluña}

La cultura, como referente turístico, ocupa un lugar destacado en el que se abren distintas opciones de acceso: agenda turística, galería y diseño, gastronomía y vino, museos y monumentos. En realidad es un buscador completo que permite localizar recursos a través de distintas opciones. Como aspecto novedoso habría que citar el acceso a clubes de producto de turismo de Cataluña y dentro de estos clubes se encuentra el de turismo cultural. Est os clubes se conciben como programas de ayuda a la comercialización para promocionar el turismo y han sido desarrollados por Turisme de Catalunya. Por último, reseñar que hay un apartado de rutas y visitas guiadas muy amplio con pequeños itinerarios de todo tipo, aunque predominan los de carácter cultural.

\section{j Comunidad Valenciana}

La of erta de turismo cultural de la w eb oficial se centra en el apartado de agenda cultural y fiestas, desde donde se puede acceder a las programaciones culturales de las ciudades y pueblos. La tipología de eventos que se puede localizar es amplia pues reconoce exposiciones, música y teatro entre otros. Además, facilita la localización de eventos por zonas costeras, pensando, sin duda, en los turistas de sol y playa que quieran practicar actividades culturales. Para localizar los recursos patrimoniales existe un buscador que of rece información municipal, donde se pueden conocer los monumentos, museos, artesanía, etc. En cuanto a las rutas, se distingue entre zonas de interior y costeras, estableciendo un modelo territorial en el que los itinerarios incluyen recursos de todo tipo.

\section{j Extremadura}

Las rutas culturales en Extremadura se organizan de dos formas: en función de su contenido (histórico-artísticas) y en base a su duración (fines de semana). En el segundo caso las rutas tienen un carácter en el que se mezclan recursos de todo tipo por su carácter territorial. Dentro de las rutas histórico artísticas se incluyen rutas temáticas, siguiendo un orden cronológico: rutas de la prehistoria, ruta del arte romano, ruta del arte islámico, ruta por la Extremadura románica, la Extremadura mudéjar, la Extremadura gótica, ruta del Renacimiento, el arte extremeño de los siglos XVII y XVIII y el arte en Extremadura en los siglos XIX y XX. Un apartado especial ocupa la Vía de la Plata como referente de itinerario turístico dentro de la región. Otros puntos de interés los constituyen la agenda, que permite localizar fiestas de interés turístico, y la información general sobre poblaciones y comarcas.

\section{j Galicia}

El patrimonio cultural ocupa un lugar muy destacado dentro de lo que se promociona en la página web oficial del turismo en Galicia. El patrimonio cultural aparece dividido por recursos como la arquitectura religiosa, arquitectura civil, conjuntos histórico-artísticos, arquitectura popular, archivos y bibliotecas, museos, parques etnográficos y centros de interpretación. "Lo que hay que ver" en Galicia se complementa con "lo que hay que hacer" $y$, en este apartado, aparece una serie de rutas cargadas de información en 
W La ciudad de Sagunto (Valencia), la Murviedro del Cantar, fue conquistada por Rodrígo Díaz de Vivar en el año 1098/ Mercedes Luzzy Arcis. Consorcio del Cid

las que se incluyen recursos de todo tipo. También se puede acceder a los folletos promocionales donde podemos encontrar información sobre el Camino de Santiago y otros recursos culturales.

\section{j Islas Baleares}

Turismo y cultura es el apartado que abre al turista la información sobre edificios singulares, museos y centros de exposición e historia y arqueología. Además, las opciones para que el turista esté informado sobre actividades culturales se centran en la agenda cultural y fiestas y espectáculos. Por último, aparece una serie de itinerarios, guiados o no, para dar a conocer la riqueza del patrimonio histórico, artístico y natural (el Modernismo en Palma, Valldemossa, Palma Monumental..).

\section{j Islas Canarias}

En Canarias la of erta sobre turismo cultural de la página web oficial se centra en las actividades programadas: fiestas, conciertos, teatro. La información viene organizada por islas, desde las que se puede acceder a una información más completa sobre recursos culturales y, en algún caso, it inerarios.

\section{j La Rioja}

En la página web de La Rioja se presta una especial atención al turismo cultural a través de un apartado denominado Reserva de culturas en el que se incluyen una gran variedad de opciones: sugerencias ("lo que el turista no se puede perder si le interesa el turismo cultural"), Camino de la
Lengua, Camino de Santiago, Monasterios, estilos artísticos, castillos, ruj nas arqueológicas, museos, pueblos y ciudades, artesanía, fiestas y tradiciones. Se trata de un conjunto de propuestas que no están diseñadas al estilo de rutas concretas, exceptuando los casos del Camino de la Lengua y del Camino de Santiago. Además se incluyen, en otro apartado, itinerarios basados en elementos del patrimonio: cultura de Rioja Baja, mosaico de culturas o fin de semana de vino y cultura.

\section{j Madrid}

La of erta cultural de la comunidad de Madrid se centra en diversos itinerarios urbanos donde la oferta museística posee un especial protagonismo a través de "El paseo del Arte" donde se incluyen los museos del Prado, Thyssen-Bornemisza y Museo Nacional Centro de Arte Reina Sofía (un itinerario único en el mundo, que discurre entre pintura y escultura, arquitectura y naturaleza). En el resto de la comunidad hay una interesante of erta de itinerarios de carácter cultural por los lugares de mayor interés. Además de todo esto, la oferta de ocio es uno de los referentes más importantes.

\section{j Murcia}

Aunque el peso del turismo de litoral es importante en Murcia, la oferta de turismo cultural se deja ver de forma clara en su portal turístico. El producto cultural y de ciudad quiere transmitir un "sinfín de testimonios del pasado". El principal canal a través del cual se promociona el turismo cultural son los recursos turísticos den- 


\section{Bibliografía}

BOTE, V.; HUÉSCAR, A.; GOY, L. (2000) Los viajes combinados de turismo cultural con destino España en los principales países europeos. Alcalá de Henares: Escuela Universitaria de Turismo, 2000

CAMPESINO FERNÁNDEZ, A. J. (coord.) (1999) Comercio, turismo y cambios funcionales en las ciudades españolas Patrimonio de la Humanidad. Cáceres: Cámara Oficial de Comercio e Industria de Cáceres, 1999

GARCíA HeRNÁNDEZ, M.; CALLE VAQUeRo, M. DE LA (2004) "Turismo urbano". En La actividad turística española en 2003. Madrid: AECIT, 2004, pp. 523-540

INSTITUTO DE ESTUDIOS TURÍSTICOS (2006a) Balance de turismo en España 2005 (en línea). Madrid: Ministerio de Industria, Economía y Comercio. <w w w . iet.tourspain.es> (consulta: 19/07/2006)
INSTITUTO DE ESTUDIOS TURISTICOS (2006b) Movimientos turísticos en frontera (FRONTUR) (en línea). Madrid: Ministerio de Industria, Economía y Comercio. $<w$ w w .iet.tourspain.es > (consulta: 19/07/2006)

INSTITUTO DE ESTUDIOS TURÍSTICOS (2006c) Encuesta de movimientos turísticos de los españoles (FAMILITUR) (en línea). Madrid: Ministerio de Industria, Economía y Comercio, 2004. <www .let.tourspain.es> (consulta: 19/07/2006)

INSTITUTO NACIONAL DE ESTADÍSTICA (2006) Encuesta anual de servicios 2004 (en línea). <www.ine.es> (consulta: 19/07/2006)

FITUR (2006) Informe de cierre FITUR 2006 (en línea). $<w$ w w. fitur.ifema.es> (consulta: 19/07/2006)

\section{Notas}

${ }^{1}$ Las previsiones de crecimiento futuro del turismo a nivel internacional aparecen reflejadas en el informe Panorama 2020 de la OMT, donde se cifra para este año un volumen de llegadas internacionales de 1.560 millones.

${ }^{2}$ Se considera que el primer turista espacial fue Dennis Tito, que llevó a cabo su viaje en el año 2001.

${ }^{3}$ El resto de actividades practicadas por estos turistas consistió en actividades de diversión en discotecas y similares en un $26,3 \%$, actividades deportivas en un $20,2 \%$, visitas a parientes y amigos en un $11 \%$ y actividades relacionadas con la gastronomía un $8 \%$.

${ }^{4}$ En el País Vasco se promociona una ruta por el patrimonio industrial; en Asturias se habla de faros como propuesta para hacer un recorrido; en Aragón de la ruta de Goya; en Castilla la Mancha, ruta de Don Quijote o en Andalucía rutas del mundo taurino.

${ }^{5}$ Es frecuente ver en las descripciones de los itinerarios of ertados, por los touroperadores, si las ciudades, pueblos o lugares visitados han sido declarados Patrimonio de la Humanidad. Asimismo, algunos operadores especializados en viajes culturales toman como referencia determinados itinerarios culturales. Es el caso, por ejemplo, de la programación of recida por el operador Viajes de Autor en su folleto verano 2006 en el que se incluyen circuitos como La Ruta de los Cátaros. Otros viajes que of rece esta empresa son significativos e incluyen recorridos que discurren por lugares Patrimonio de la Humanidad: la ruta de Alejandro Magno 0 Catedrales medievales de Inglaterra son algunos ejemplos.

${ }^{6}$ Entendemos por circuitos aquellos itinerarios comerciales que terminan en el lugar de inicio.

${ }^{7}$ La Ley $21 / 1995$, reguladora de los viajes combinados define al viaje combinado como la combinación previa de por lo menos, dos de los siguientes elementos: vendida u of recida en venta con arreglo a un precio global, cuando dicha prestación sobrepase las veinticuatro horas 0 incluya una noche de estancia: transporte, alojamiento, otros servicios turísticos no accesorios del transporte 0 del alojamiento y que constituyan una parte significativa del viaje combinado.

${ }^{8}$ El todo incluido en sol y playa, que es muy popular en países del Caribe, consiste en un paquete que incluye: transporte, traslados in-out, alojamiento, comidas y bebidas dentro del establecimiento hotelero contratado y uso de determinados servicios. Con esta modalidad el turista permanece la mayor parte del tiempo en el hotel.

${ }^{9} \mathrm{Al}$ margen de los servicios incluidos pueden aparecer algunas visitas opcionales a pagar en destino y las bebidas en las comidas. Distintos mayoristas, como Cóndor Vacaciones o Panavision, utilizan esta fórmula en numerosos destinos europeos. Por ejemplo, la mayorista Panavision en su folleto Circuitos por Europa, Canadá y USA primavera verano 2006 of erta circuitos por destinos europeos como Alemania o Italia donde se incluyen en el
OMT (2006) Datos esenciales del turismo. Edición 2005 (en línea). <w w w.w orld-tourism.org > (consulta: 19/07/2006)

VÁZQUEZ, R. (2005) "Recursos culturales y diseño del producto $y$ la oferta de turismo cultural: importancia de las actividades de marketing". En GÓMEZ, M. A.; MONDÉJAR, J. A.; SEVILLA, C. (coord.) Gestión del turismo cultural y de ciudad. Cuenca: Universidad de Castilla-La Mancha, 2005, pp. 29-60

VERA, J.F. (coord.) (1997) Análisis territorial del turismo. Madrid: A riel Geografía, 1997

VOGELER C.; HERNÁNDEZ ARMAND, E. (1999) Estructura y organización del mercado turístico. Madrid: Centro de Estudios Ramón Areces, 1999 precio: transporte, manutención, varias visitas panorámicas con guía local de importantes ciudades alemanas algunas de las cuales han sido declaradas por la UNESCO Patrimonio de la Humanidad, visitas con guía y entrada a algunos museos.

${ }^{10}$ Las fórmulas aparecidas en la página de inicio son Cultura y Ocio (Cantabria), Cultura (País Vasco), Cultural y Ciudad (Murcia), Reserva de culturas (La Rioja), Turismo Cultural (Castilla y León), Cultura en la naturaleza (Navarra), Visitas culturales (Andalucía)...

${ }^{11}$ Entendemos por rutas temáticas aquellas en las que los recursos responden a una misma tipología (castillos, monasterios, románico, etc.) y territoriales, aquellas que se basan en un marco territorial y en las que se pueden incluir recursos de todo tipo (naturaleza, monumentos, actividades, etc.).

\footnotetext{
${ }^{12}$ Entre los recursos de Internet destacamos los siguientes: $w w w$.andalucia.org, www .canariasturismo.com, www.castillalamancha.es, www.comunitatvalenciana.com www gencat.net/turistex_nou, ww w illesbalears.es, $w w w$.inf oasturias.com, $w w w$.lariojaturismo.com, ww w.madrid.org/ceconomia/tematico/con mad/entrada, ww w .murciaturisticas.es, w w w . paisvascoturismo.net, www.turismodearagon.com,

www .turismodecantabria.com ww w.turismoextremadura.es, ww w turismo.navarra.es y ww w.turgalicia.es
} 